\title{
Prevalence of $A B O$ blood groups in patients with haematological malignancies: a retrospective study
}

\begin{abstract}
Background: The pattern and distribution of Haematological malignancies vary depending on age, sex and geographical location. Studies on the association between Haematological cancers and ABO blood types have been largely conflicting. The objective of our study was to determine the distribution of $\mathrm{ABO}$ blood groups among patients with Haematological malignancies and to correlate with age and gender.
\end{abstract}

Materials and Methods: This was a chart based observational descriptive study involving the review of records of 85 patients with various Haematological malignancies in Father Muller Medical College Hospital for a period of two years from July 2017- June 2019. Age, gender, malignant condition, $\mathrm{ABO}$ and $\mathrm{Rh}$ blood group were collected for each case. Data was analyzed statistically by frequency and percentage.

Results: The peak age incidence for various Haematological malignancies was in the fifth and sixth decades of life with a mean age of 47.The male to female sex ratio was almost 1:1. Majority of the patients were of the $\mathrm{O}$ blood group and an association of $\mathrm{O}$ blood group with various hematological malignancies with male preponderance was noted. Altogether, Leukemias were the most common Haematological malignancy observed in this study.

Conclusion: The distribution, age and sex ratio of Haematological malignancies in our study was comparable to those reported by other authors with Acute Myeloid Leukemia (AML) being the most common Haematological malignancy in our environment. There was no significant association between Haematological cancers and ABO blood type of the patients, but probably individuals with $\mathrm{O} \mathrm{Rh}$ positive blood group are more prone to Haematological malignancies.

Keywords: haematological malignancies, blood group, ABO
Volume 8 Issue I - 2020

\author{
Ashwin Mathew,' Kirana Pailoor, ${ }^{2}$ Konchady \\ Deepthi Suresh Shenoy ${ }^{3}$ \\ 'Final year Pathology Postgraduate Resident, Father Muller \\ Medical College, India \\ ${ }^{2}$ Associate Professor and Incharge Blood Bank, Department of \\ Pathology, Father Muller Medical College, India \\ ${ }^{3}$ 2nd year MBBS student, Father Muller Medical College, India
}

Correspondence: Dr. Kirana Pailoor, Associate Professor, Department of Pathology, Father Muller Medical College, Kankanady, Mangaluru -575002, Tel 9448953716,

Email dockirana@yahoo.co.uk

Received: November 07, 2019 | Published: February 28, 2020

\section{Introduction}

Haematological malignancies are a group of cancers that affect the bone marrow, blood and lymph nodes. ${ }^{1}$ Globally, Haematological malignancies account for $7.5 \%$ and $6.4 \%$ respectively of male and female cancers. ${ }^{2}$ For a few of these Haematological cancers, risk factors like environmental factors and viral pathogens have been implicated however, the etiology still remains largely unknown.

The ABO blood group discovered by Karl Landsteiner in 1901 is the most important and most antigenic of the blood group system. The ABO antigens are fully developed after 2-4 years of age ${ }^{3}$ and are expressed on the surfaces of erythrocyte membranes alongside large number of normal human cells and tissues including body fluids as well as some tumors and whose expression remains constant throughout life. Loss of $\mathrm{A}, \mathrm{B}$ or $\mathrm{H}$ antigens from the surface of RBCs is recognized as a recurrent observation in Haematological malignancies. Thus, loss of ABO expression in the population of red cells derived from a malignant stem cell is an indicator of genetic changes that have occurred in the malignant stem cell.

Association of blood groups to some disease conditions like association with Stomach, Neurologic, Salivary gland, Kidney, Cervical and other solid tumors have been studied This study intends to find a probable link between blood groups and Haematological malignancies.
Earlier studies have shown that Leukemias and Lymphomas comprised the majority of cases belonging to O-blood group ${ }^{3}$ with male preponderance in the fifth and sixth decades of life. ${ }^{1}$

Patients with Acute Leukemia had an increased frequency of the A blood group ${ }^{4,5}$ in men and $\mathrm{O}$ bloodgroup in females ${ }^{6}$ and that an alteration in $\mathrm{ABO}$ antigens might be associated with an increased risk of Acute Lymphocytic Leukemia (ALL). ${ }^{7}$ The mean survival for Acute Leukemias was found to be less than a month and for Chronic Leukemias, it ranged between 24 and 45 months. On division of the leukemic patients into subgroups, alterations in the frequencies of $\mathrm{ABO}$ phenotypes is noticed only in CLL. ${ }^{8}$

The possible genetically determined connection between blood groups and susceptibility to Acute Leukemias might be a good explanation for the high frequency of blood group O. Changes in blood-group characteristics of patients with Acute Leukemias in the course of disease are well known but it cannot be used for explaining sex differences in blood group distributions ${ }^{6}$ as sex and blood group relationships does not influence survivorship in Acute Leukemia. ${ }^{9}$

The clinical significance of the ABO blood group system extends beyond transfusion medicine as several reports have suggested an important involvement in the development of neoplastic disorders. ${ }^{10}$ Very few studies have evaluated the frequency and distribution of $A B O$ blood groups among patients with Haematological malignancies and their association in our environment which were largely inconsistent. 
The objectives of this study were to determine the frequency and distribution of the $\mathrm{ABO}$ blood groups of patients suffering from different Haematological malignancies and to determine their association. We also aimed to identify the more frequent gender and age group affected and compare with the findings from other studies.

\section{Materials and methods}

It was a time bound chart based observational descriptive study involving 85 patients with various Haematological malignancies during a period of two years from $1^{\text {st }}$ July $2017-30^{\text {th }}$ June 2019 in Father Muller Medical College Hospital, Kankanady, Mangalore. Information on the type of Haematological cancers, the age and sex of the subjects and their $\mathrm{ABO}$ blood types were extracted from hospital database. All records of patients with confirmed diagnosis of any of the Haematological malignancies with complete clinical and laboratory records were included in the study. However, patients with incomplete records and those with dual malignancies were excluded. The cases were categorized with respect to age, gender, malignant condition, $\mathrm{ABO}$ and $\mathrm{Rh}$ blood group and statistically analyzed by percentage and frequency. Institutional ethical clearance was obtained.

\section{Results}

A total of 85 patients with Haematological malignancies were reviewed during the study period. Little more than half of the subjects were females $(43 / 85,51 \%)$, being male to female sex ratio of nearly $1: 1$ (Figure 1). In relation of the age of the patients with Haematological malignancies, the mean age of the subjects was 47 years with a range of 02- 92 years and with a peak age incidence between fifth and sixth decades of life (Figure 2).

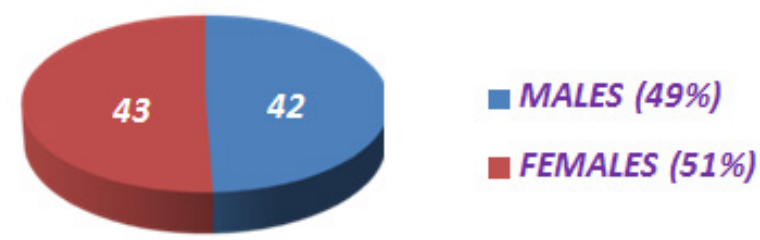

Figure I Sex distribution of subjects.

Analysis of the gender of 85 patients with various Hematological malignancies assisted at Father Muller Medical College Hospital, Kankanady, Mangalore during a period of two years from Ist July 2017-30th June 2019,showing no statistical differences between male and female.

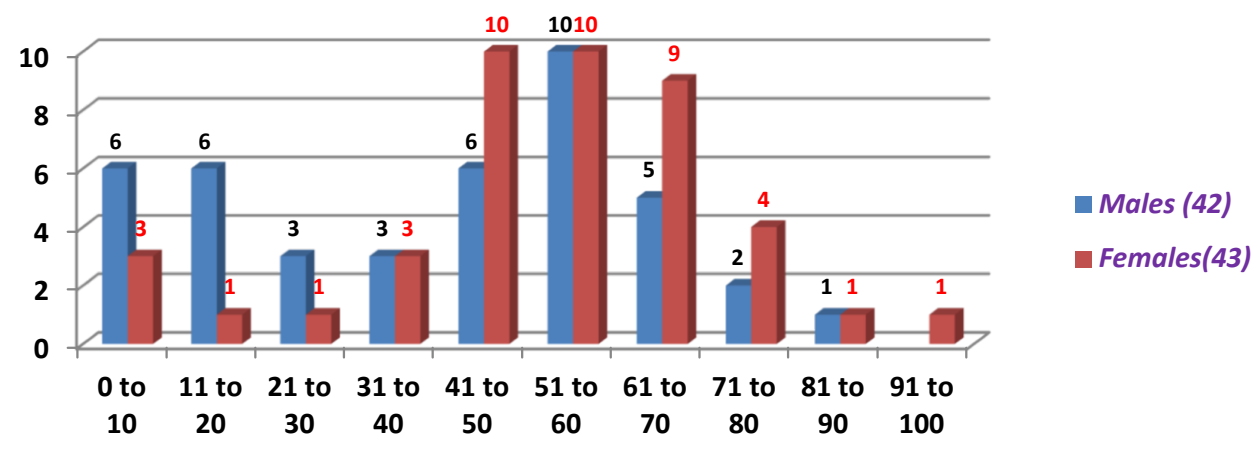

Figure 2 Age-gender wise distribution.

Analysis of the age of the patients in relation to with Haematological malignancies revealed that its peak incidence was between fourth and fifth decades of life.

When the patients were classified according to the Haematological disease, Acute Lymphocytic Leukemia (12/85;14\%) was found predominantly in adults less than 20 years of age. Acute Myeloid Leukemia (8/85) and Chronic Myeloid Leukemia (3/85) was predominantly found in adults in the fifth decade of life. Chronic Lymphocytic leukemia was predominant in adults of 51-80 years of age. Plasma Cell Neoplasm (11/85) and Non Hodgkin Lymphoma $(2 / 85)$ was common among adults of 51-60 years of age.

The gender of patients classified according to the Haematological disease were more common in male subjects than females (Table 1) (Figure 3), except for Acute Myeloid Leukemia (AML) and Plasma Cell Neoplasms (PCN).

Table I Age distribution of the various Haematological malignancies

\begin{tabular}{|c|c|c|c|c|c|c|c|c|c|c|c|c|c|c|c|c|}
\hline \multirow[t]{2}{*}{ Age Group } & \multicolumn{2}{|l|}{ AML } & \multicolumn{2}{|c|}{ ALL } & \multicolumn{2}{|c|}{ CML } & \multicolumn{2}{|c|}{ CLL } & \multicolumn{2}{|c|}{ PCN } & \multicolumn{2}{|c|}{ NHL } & \multicolumn{2}{|c|}{ Total } & \multirow[t]{2}{*}{ Frequency } & \multirow[t]{2}{*}{ Percentage } \\
\hline & $M$ & $\mathbf{F}$ & $\mathbf{M}$ & $\mathbf{F}$ & $\mathbf{M}$ & $\mathbf{F}$ & $\mathbf{M}$ & $\mathbf{F}$ & $M$ & $\mathbf{F}$ & $\mathbf{M}$ & $\mathbf{F}$ & $\mathbf{M}$ & $\mathbf{F}$ & & \\
\hline $0-10$ & 3 & 0 & 3 & 3 & 0 & 0 & 0 & 0 & 0 & 0 & 0 & 0 & 6 & 3 & 9 & $11 \%$ \\
\hline 20-Nov & 0 & I & 6 & 0 & 0 & 0 & 0 & 0 & 0 & 0 & 0 & 0 & 6 & 1 & 7 & $8 \%$ \\
\hline
\end{tabular}


Table continue

\begin{tabular}{|c|c|c|c|c|c|c|c|c|c|c|c|c|c|c|c|c|}
\hline \multirow[t]{2}{*}{ Age Group } & \multicolumn{2}{|c|}{ AML } & \multicolumn{2}{|c|}{ ALL } & \multicolumn{2}{|c|}{ CML } & \multicolumn{2}{|c|}{ CLL } & \multicolumn{2}{|c|}{ PCN } & \multicolumn{2}{|c|}{ NHL } & \multicolumn{2}{|c|}{ Total } & \multirow[t]{2}{*}{ Frequency } & \multirow[t]{2}{*}{ Percentage } \\
\hline & $M$ & $\mathbf{F}$ & $M$ & $\mathbf{F}$ & $M$ & $\mathbf{F}$ & $M$ & $\mathbf{F}$ & $M$ & $\mathbf{F}$ & $\mathbf{M}$ & $\mathbf{F}$ & M & $\mathbf{F}$ & & \\
\hline $21-30$ & 1 & 1 & I & 0 & 1 & 0 & 0 & 0 & 0 & 0 & 0 & 0 & 3 & I & 4 & $5 \%$ \\
\hline $31-40$ & 2 & 2 & 0 & 1 & I & 0 & 0 & 0 & 0 & 0 & 0 & 0 & 3 & 3 & 6 & $7 \%$ \\
\hline $41-50$ & 3 & 5 & 0 & 1 & 2 & I & 0 & 0 & 1 & 2 & 0 & 1 & 6 & 10 & 16 & $19 \%$ \\
\hline $51-60$ & 0 & 4 & 0 & 0 & 1 & I & 1 & 0 & 6 & 5 & 2 & 0 & 10 & 10 & 20 & $24 \%$ \\
\hline $61-70$ & 0 & 3 & 0 & 0 & 1 & 0 & 0 & 0 & 3 & 6 & $\mathrm{I}$ & 0 & 5 & 9 & 14 & $16 \%$ \\
\hline $71-80$ & 0 & 2 & 0 & 0 & 0 & 0 & 1 & 0 & 1 & 2 & 0 & 0 & 2 & 4 & 6 & $7 \%$ \\
\hline $81-90$ & 0 & 0 & 0 & 0 & 0 & 0 & 0 & 0 & 1 & I & 0 & 0 & 1 & I & 2 & $2 \%$ \\
\hline $91-100$ & 0 & I & 0 & 0 & 0 & 0 & 0 & 0 & 0 & 0 & 0 & 0 & 0 & I & 1 & $1 \%$ \\
\hline Total & 9 & 19 & 10 & 5 & 6 & 2 & 2 & 0 & 12 & 16 & 3 & 1 & 42 & 43 & 85 & $100 \%$ \\
\hline
\end{tabular}

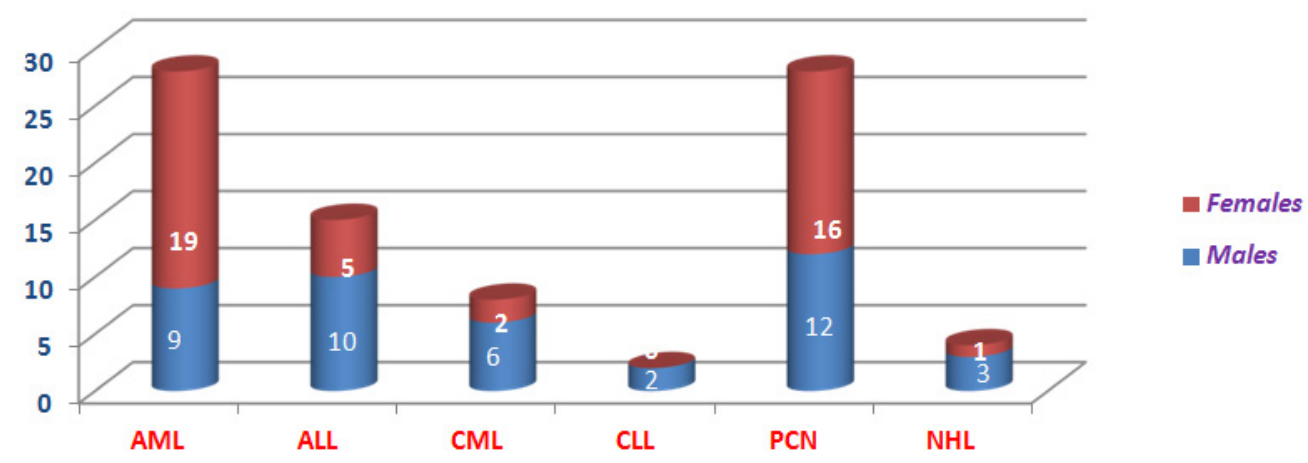

Figure 3 Gender wise distribution of various malignancies.

Analysis of the gender in relation to various Haematological malignancies revealed that hematological malignancies was more common in male patients than females except for Acute Myeloid Leukemia (AML) and Plasma Cell Neoplasms (PCN).

The analysis of the Haematological malignancy showed that Leukemias were the most common Haematological disease found in our study, accounting to 53 cases $(62 \%)$ with an equal gender ratio, while Acute Myeloid Leukemia (AML) was the most frequent Leukemia seen comprising 28 cases (33\%). The distribution of various Haematological malignancies were as follows, Acute Myeloid Leukemia (AML) n=28 (33\%), Plasma Cell Neoplasms (PCN) $n=28$ (33\%), Acute Lymphocytic Leukemia (ALL) $n=15$ (18\%), Chronic Myeloid Leukemia (CML) $\mathrm{n}=8(9 \%)$, Non Hodgkins Lymphoma (NHL) $\mathrm{n}=4$ (5\%) and Chronic Lymphocytic Leukemia (CLL) $\mathrm{n}=2$ $(2 \%)$. Acute Leukemia $\mathrm{n}=43(51 \%)$ were more common than Chronic Leukemia cases $n=10(11 \%)$ (Figure 4).

According to the $\mathrm{ABO}$ and $\mathrm{Rh}$ blood system, $\mathrm{O} \mathrm{Rh}$ positive blood type $\mathrm{n}=30(35 \%)$ comprised majority of the subjects followed by A1 Rh positive $n=23(28 \%)$ and $B$ Rh positive $n=22(26 \%)$ while there were no patients belonging to A Rh negative groups. Collectively, subjects with the non O blood type $n=54(64 \%)$ were more than the O blood type $n=31(36 \%)$ and $50 \%$ of individuals of $\mathrm{O}$ blood group were males. CML and CLL were commoner among $\mathrm{O}$ Rh positive blood group $\mathrm{n}=4$ and $\mathrm{n}=2$ respectively, than non $\mathrm{O}$ groups while AML,ALL,PCN and NHL were commoner among non $\mathrm{O}$ blood groups than the $\mathrm{O}$ blood group (Table 2).

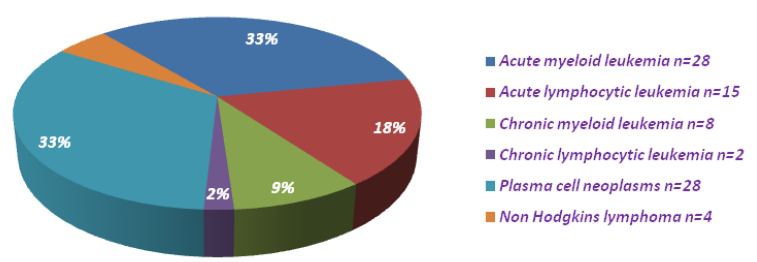

Figure 4 Haematological malignancies of subjects.

Analysis of the incidence of Haematological malignancies revealed that AML and PCN were the most common whereas CLL was found to be the least common among all the Haematological malignancies.

As patients with Haematological malignancy needs blood transfusion, we verified the $\mathrm{ABO}$ and $\mathrm{Rh}$ blood system from blood donors in Kankanady from July 2017 to June 2019. The total number of were 16871. Out of these, 15973 were male and 898 were female. The most common blood group was $\mathrm{O}(36.6 \%)$, followed by $\mathrm{B}$ (29.4\%), $\mathrm{A}(27.3 \%)$ and $\mathrm{AB}(6.67 \%)$. According to the results of this study, $\mathrm{O} \mathrm{Rh}$ positive blood group was the most common in patients with Leukemias and Lymphomas. 
Table 2 The different blood groups of subjects

\begin{tabular}{|c|c|c|c|c|c|c|c|c|c|c|c|c|c|c|c|c|}
\hline \multirow[t]{2}{*}{ Blood Groups } & \multicolumn{2}{|c|}{ AML } & \multicolumn{2}{|c|}{ ALL } & \multicolumn{2}{|c|}{ CML } & \multicolumn{2}{|c|}{ CLL } & \multicolumn{2}{|c|}{ PCN } & \multicolumn{2}{|c|}{ NHL } & \multicolumn{2}{|c|}{ Total } & \multirow[t]{2}{*}{ Frequency } & \multirow[t]{2}{*}{ Percentage } \\
\hline & $\mathbf{M}$ & $\mathbf{F}$ & $\mathbf{M}$ & $\mathbf{F}$ & $\mathbf{M}$ & $\mathbf{F}$ & $\mathbf{M}$ & $\mathbf{F}$ & $\mathbf{M}$ & $\mathbf{F}$ & $\mathbf{M}$ & $\mathbf{F}$ & M & $\mathbf{F}$ & & \\
\hline O Rh Positive & 2 & 4 & I & 3 & 3 & I & 2 & 0 & 6 & 7 & I & 0 & 15 & 15 & 30 & $35 \%$ \\
\hline O Rh Negative & 0 & I & 0 & 0 & 0 & 0 & 0 & 0 & 0 & 0 & 0 & 0 & 0 & 1 & 1 & $1 \%$ \\
\hline Al Rh Positive & 5 & 6 & 4 & I & I & I & 0 & 0 & 2 & 2 & I & 0 & 13 & 10 & 23 & $28 \%$ \\
\hline Al Rh Negative & 0 & 0 & 0 & 0 & 0 & 0 & 0 & 0 & 0 & 0 & 0 & 0 & 0 & 0 & 0 & $0 \%$ \\
\hline A2 Rh Positive & 0 & 3 & 0 & 0 & 0 & 0 & 0 & 0 & 0 & I & 0 & 0 & 0 & 4 & 4 & $5 \%$ \\
\hline A2 Rh Negative & 0 & 0 & 0 & 0 & 0 & 0 & 0 & 0 & 0 & 0 & 0 & 0 & 0 & 0 & 0 & $0 \%$ \\
\hline B Rh Positive & 2 & 3 & 3 & I & 2 & 0 & 0 & 0 & 4 & 6 & 0 & I & 11 & 11 & 22 & $26 \%$ \\
\hline B Rh Negative & 0 & 1 & 0 & 0 & 0 & 0 & 0 & 0 & 0 & 0 & I & 0 & 1 & 1 & 2 & $2 \%$ \\
\hline AIB Rh Positive & 0 & 1 & I & 0 & 0 & 0 & 0 & 0 & 0 & 0 & 0 & 0 & 1 & 1 & 2 & $2 \%$ \\
\hline AIB Rh Negative & 0 & 0 & 1 & 0 & 0 & 0 & 0 & 0 & 0 & 0 & 0 & 0 & 1 & 0 & I & $1 \%$ \\
\hline Total & 9 & 19 & 10 & 5 & 6 & 2 & 2 & 0 & 12 & 16 & 3 & I & 42 & 43 & 85 & $100 \%$ \\
\hline
\end{tabular}

Table 3 Blood group of Kankanady population

\begin{tabular}{llll}
\hline Blood groups & Rh postitive & Rh negative & Total \\
\hline A & $444 I$ & 170 & $46 I I(27.3 \%)$ \\
B & 4590 & 379 & $4969(29.4 \%)$ \\
AB & 1104 & 151 & $1125(6.67 \%)$ \\
O & 5736 & 428 & $6164(36.6 \%)$ \\
\hline
\end{tabular}

\section{Discussion}

The relationship between gender, race, geographic location and various childhood Haematological malignancies are well known. However, the association between blood groups and these malignancies is not well established.?

Acute Myeloid Leukemia and Plasma Cell Neoplasms were not only the most common malignancies encountered in our study but also the most frequent malignancies in majority of the females. Chronic Leukemias were more commonly seen in males similar to the study by Babatunde and colleagues. ${ }^{3}$ Stastical analysis of the data revealed $\mathrm{p}$ value $=0.44$ which is significant.Furthermore, the majority of Haematological malignancies were observed among patients in the fifth and sixth decades of life similar to the study by Ino-Ekanem and colleagues ${ }^{1}$ and Babatunde and colleagues. ${ }^{3}$ The peak incidence of CML was the middle aged group of individuals and that of CLL was in the elderly group which is in agreement with the study by Babatunde and colleagues. ${ }^{3}$ But in case of ALL, it showed a shift to the lower age group of $0-20, n=12(80 \%)$ which is in agreement to a study by Babatunde and colleagues ${ }^{3}$ and Meliha Sakić and colleagues. ${ }^{11}$ The differences observed in the age incidences with the western countries affecting seventh decade in a study done by Smith A and colleagues ${ }^{12}$ could be attributed largely to our relatively younger population, shorter life expectancy due to poor socio-economic status and environmental factors.

In this study, the majority of the patients were of the O-blood type $\mathrm{n}=31 / 85(36 \%)$ similar to the study by Ino-Ekanem and colleagues ${ }^{1}$ while the $\mathrm{AB}$ blood group was the least common similar to the study by Janardhana and colleagues. ${ }^{8}$ Analysis of the gender of patients with various Haematological malignancies revealed no statistical differences between male and female. With Acute Leukemia highlighted to be the most common amongst Leukemias $n=43(51 \%)$, our study also showed an increase in the frequency of $\mathrm{O} R \mathrm{R}$ positive blood group $\mathrm{n}=7$ (70\%) among female patients with Acute Leukemia which correlates with findings of study by Nagy and colleagues ${ }^{6}$ and Mustachhi and colleagues. ${ }^{9}$ Plasma Cell Neoplasms also showed an increase in frequency of $\mathrm{O} R \mathrm{R}$ positive blood group $\mathrm{n}=13(46.4 \%)$ followed by B Rh positive blood group $\mathrm{n}=10$ (35.7\%). Majority of the cases of Chronic Leukemias were also $\mathrm{O}$ Rh positive blood group $\mathrm{n}=6(60 \%)$ which is in concordant with a study by Ino-Ekanem and colleagues ${ }^{1}$ but discordant with the study by Iodice and colleagues ${ }^{4}$ and Janardhana and colleagues. ${ }^{8}$

As an idea for future research, Alavi S and colleagues ${ }^{7}$ proposed using newborn cord blood for determination and redetermination of blood groups at intervals evaluating its role as risk factors of Haematological malignancies and documented that among patients with Leukaemia, those with AML had an increased frequency of A blood group similar to findings in our study with an increased frequency of A1 blood phenotype in Acute Leukemia with results indicating a correlation between the incidence of blood group A and Acute Leukemia. ${ }^{4,5} \mathrm{ABO}$ antigens are present but not fully developed until 2-4 years of age. Blood grouping is done at intervals and if there is loss of $\mathrm{AB}$ antigens,it may be a risk factor. Interestingly majority of 
cases with AB Blood group in our study $n=2(66 \%)$ had ALL which supports the findings of a study by Tavasolian and colleagues ${ }^{13}$ who demonstrated that $\mathrm{AB}$ blood group was associated with a higher risk of ALL. Non Hodgkin's Lymphoma $n=4$ (4.7\%) and CLL n=2 (2.3\%) were the least common cases which is not in accordance with the study by Babatunde and colleagues. ${ }^{3}$

Overall, this study suggests the probability that females with $\mathrm{O} R \mathrm{Rh}$ positive blood group are more prone to Acute Leukemia and Plasma Cell Neoplasms and that males with $\mathrm{O}$ Rh positive blood group are more prone to Chronic Leukemias. The high frequency of $\mathrm{O}$ group in females is due to genetically determined correlation between blood group and susceptibility to Acute Leukemia. This study also points to an increased proportion of $\mathrm{A} 1 \mathrm{Rh}$ positive blood group in Acute Leukemia and an increased risk of ALL in AB blood group.

The frequency of $\mathrm{ABO}$ blood group among the ethnic population is variable. In a study done in Tanzania ,Africa by Jahanpour and colleagues, ${ }^{14}$ blood group $\mathrm{O}$ was most common among the donors, followed by A,B and AB. In another study done in Gujarat, a state in India, by Raja KA and colleagues ${ }^{15}$ it was observed that $\mathrm{B}$ blood group was the most common, followed by $\mathrm{O}, \mathrm{A}$ and $\mathrm{AB}$. According to the results of this study, blood group $\mathrm{O}$ was most the common, followed by $\mathrm{B}, \mathrm{A}$ and $\mathrm{AB}$.

\section{Conclusion}

The distribution, age and sex ratio of Haematological malignancies in our study was comparable to those reported by other authors with AML being the most common Haematological malignancy in our environment. O Rh positive was found to be the most common blood group in majority of the Haematological malignancies, however the majority of the population belongs to this blood group. The gender wise distribution showed a slight female preponderance and age wise distribution revealed malignancies occurring most commonly in 40-60 years of age. There was no significant association between Haematological cancers and ABO blood type of the patients, but probably A1 blood phenotype link in Acute Leukemia and individuals with $\mathrm{O}$ Rh positive blood group were more prone to Haematological malignancies could be deduced. However, for a definitive conclusion or association between blood groups and Haematological malignancies, our sample size was small. With mean survival for acute leukemias less than chronic leukemias, the need of knowing more common blood groups and risks in Haematological malignancies can establish an association between them thereby, serving as a potential epidemiological marker to identify high risk population and with interdisciplinary approach for better and effective management of Haematological malignancies by supplying safe blood for these patients who frequently need high volumes of blood products.

\section{Acknowledgments}

None.

\section{Conflicts of interest}

The author declares no conflicts of interest.

\section{Funding}

None.

\section{References}

1. Ino-Ekanem M, Ekwere T, Ekanem A. The Frequency and Distribution of ABO Blood Groups in Patients with Haematological Cancers in Uyo, Nigeria: A Hospital Based Retrospective Study. International Blood Research \& Reviews. 2018;8(3):1-8.

2. Ferlay J, Soerjomataram I, Dikshit R, et al. Cancer incidence and mortality worldwide: Sources, methods and major patterns in GLOBOCAN 2012. Int J Cancer. 2015;136(5):E359-E86.

3. Babatunde A, Amiwero C, Olatunji P, et al. Pattern of haematological malignancies in Ilorin, Nigeria: A ten year review. The Internet Journal of Haematology. 2008;5(2):10.

4. Iodice $\mathrm{S}$, Maisonneuve $\mathrm{P}$, Botteri $\mathrm{E}$, et al. $\mathrm{ABO}$ blood group and cancer. Eur J Cancer. 2010;46(18):3345-3350.

5. Shirley R, Desai R. Association of Leukaemia and Blood Groups. J Med Gen. 1965;2(3):189-191.

6. Nagy P, Jakó J, Kiss A, et al. Sex-linked difference in blood-group distribution among patients suffering from acute leukaemias. $\mathrm{Br} J$ Haematol. 1981;48(3):507-512.

7. Alavi S, Ashraf H, Rashidi A, et al. Distribution of ABO Blood Groups in childhood Acute Leukemia. Pediatric Hematol Oncol. 2006;23(8):611617.

8. Janardhana V, Propert D, Green R. ABO blood groups in hematologic malignancies. Cancer Genet Cytogenet. 1991;51(1):113-120.

9. Mustacchi P, Shoenfeld E, Lucia S. Survival in Acute Leukemia: the influence of blood groups, sex, and age at onset. Ann Intern Med. 1960;52(5):1099.

10. Franchini M, Favaloro EJ, Targher G, et al. ABO blood group, hypercoagulability, and cardiovascular and cancer risk. Crit Rev Clin Lab Sci. 2012;49(4):137-149.

11. Sakić M. Distribution of ABO blood group in children with Acute Leukemias. Journal of Health Sciences. 2012;2(3):220-223.

12. Smith A, Howell D, Patmore R, et al. Incidence of haematological malignancy by sub-type: a report from the Haematological Malignancy Research Network. British Journal of Cancer. 2011;105(11):1684-1692.

13. Tavasolian F, Abdollahi E, Vakili M, et al. Relationship between ABO blood group and Acute lymphoblastic leukaemia. Iran J Ped Hematol Oncol. 2014;4(1):1-4.

14. Jahanpour O, Pyuza JJ, Ntiyakunze EO, et al. ABO and Rhesus blood group distribution and frequency among blood donors at Kilimanjaro Christian Medical Center, Moshi, Tanzania. BMC Res Notes. 2017;10(1):738.

15. Raja KA, Dobariya GH, Unanagar CA, et al. Frequency and distribution of $\mathrm{ABO}$ and $\mathrm{Rh}$ blood groups among blood donors in tertiary care hospital of South Gujarat, India. Int $J$ Res Med Sci. 2016;4(12):5377-5381. 